\title{
Bloodstream Infections in Late-Stage Acquired Immunodeficiency Syndrome Patients Evaluated by a Lysis Centrifugation System
}

\author{
RC Rosas/*, R Salomão/*, DA da Matta, HV Lopes**, AC Pignatari, AL Colombo/+ \\ Hospital São Paulo, Universidade Federal de São Paulo, Rua Napoleão de Barros 715, 04024-002 São Paulo, SP, Brasil \\ *Hospital e Maternidade Santa Marcelina, São Paulo, SP, Brasil **Hospital Heliópolis, São Paulo, SP, Brasil
}

Opportunistic infections, which affect acquired immunodeficiency syndrome (Aids) patients, are frequently disseminated and may cause bloodstream infections (BSI). The aim of this study was to evaluate the main causes of BSI in Aids patients with advanced stage of the disease, with special emphasis on the identification of fungemia. During a 21 months period, all patients with Aids $(C D 4<200)$ and febrile syndrome admitted to 3 university hospitals were systematically evaluated. For each patient presenting fever, a pair of blood cultures was collected and processed by using a commercial lysis-centrifugation system.

One hundred and eleven patients ( 75 males) with a mean age of 36 years (median 33 years) and mean CD4 count of 64 cells $/ \mathrm{ml}$ were included. Among the 111 patients evaluated we documented 54 episodes of BSI, including 46 patients with truly systemic infections and 8 episodes considered as contaminants. BSI were caused by grampositive bacteria (43\%), fungi (20\%), gram-negative bacteria (15\%), mycobacteria (15\%), and mixed flora (7\%). The crude mortality rate of our patients was 39\%, being 50\% for patients with BSI and $31 \%$ for the others. In conclusion, BSI are a common related to systemic infections on Aids patients with advanced stage of disease and is associated with a high rate of mortality.

Key words: acquired immunodeficiency syndrome (Aids) - bloodstream infection - lysis centrifugation

Systemic infections on acquired immunodeficiency syndrome (Aids) patients frequently have the concomitant presence of pathogens on blood due to the failure of the host defenses to contain an infection at the primary focus. Aids patients present a disorder of the immune system mainly related to functional abnormalities and quantitative depletion of CD4+ T-lymphocytes, but it also may include deficiency of B-lymphocytes, macrophages and polymorphonuclear cells. This complex disorder of the immune system leads not only to the increased susceptibility of human immunodeficiency virus (HIV)-patients to opportunistic pathogens but also to bacterial agents (Tumbarello et al. 1995). Besides immunological changes, the intravenous drug abuses as well as the extensive use of central venous catheters for therapeutic proposes are factors that may corroborate to predispose the development of bloodstream infections (BSI) in HIVpatients. In addition, hospitalized Aids patients may also develop bacteremia as a complication of invasive medical procedures such as urinary catheterization and mechanical ventilation (Tumbarello et al. 1995, Petrosillo et al. 2002). There is scarce information about the pathogens related to bloodstream infections on Aids patients admitted on Brazilian tertiary care hospitals. We conducted a crosssectional study to evaluate epidemiologic characteristics

This study was sponsored by the Conselho Nacional para o Desenvolvimento Científico e Tecnológico (CNPq), grants 300686/97-8.

${ }^{+}$Corresponding author. Fax +55-11-5549.6585. E-mail: colomboal@terra.com.br

Received 19 September 2002

Accepted 26 March 2003 and species distribution of pathogens related to bloodstream infections documented on Aids patients, with special emphasis on fungemic episodes.

\section{PATIENTS AND METHODS}

During a 21 month-period we evaluated Aids inpatients at advanced stage of the disease who experimented more than 3 days of fever at any time during the hospitalization at 3 tertiary care hospitals from São Paulo, Brazil: Hospital e Maternidade Santa Marcelina, Hospital Heliópolis and Hospital São Paulo, Universidade Federal de São Paulo.

We selected all patients older than 13 years old, who had a febrile syndrome (temperature $\geq 38^{\circ} \mathrm{C}$ ) and late stage of Aids confirmed by HIV serology and CD4+ T lymphocyte count $\leq 200$ cells $/ \mathrm{ml}$. We excluded all patients who had the identification of the etiologic agent of the febrile syndrome before hospitalization. All enrolled patients had a pair of blood cultures collected at the admission and any time during the hospitalization if they developed unknown origin fever after the admission. The blood cultures were aseptically collected at no less than hourly intervals. A $10 \mathrm{ml}$ blood sample from each culture collected was directly inoculated into isolator system vial (Wampole Laboratories, Cranbury, New Jersey, USA) and processed according to the manufacturer's instructions. In brief, the bottles were centrifuged for $30 \mathrm{~min}$ and aliquots of the obtained sediment were seeded in blood agar, chocolate agar, brain-heart infusion, Sabouraud dextrose agar and Löwenstein-Jensen culture media. The cultures were incubated at $35^{\circ} \mathrm{C}$ during a period of up to 45 days.

The investigator visited the selected patients once a week to report demographic and clinical data, as well as all laboratory results related to the investigation of the 
febrile episode. For each patient the following information was systematically collected: sex, age, risk factors for HIV infection, previous opportunistic infections, signs and symptoms of the infection, results of laboratory tests of interest to the case, use of antimicrobial agents, presence of a central venous catheter (CVC) and outcome.

The patients were followed from the admission up to discharge or death. It is important to note that except for the blood cultures that were systematically collected, all lab tests and other diagnostic procedures were only requested by individual decision of the assistant physician.

The bacteria isolates were identified by means of microscopical examination as well as biochemical tests. The mycobacteria were identified by their morphology on ZiehlNielsen stain, as well as by biochemical tests (NCCLS 1995). Yeasts were identified based on their morphological characteristics and biochemical profile evaluated by the API 20C AUX disposable plastic galleries (BioMérieux SA, Marcy-l'Etoille, France). Filamentous and dimorphic fungi were identified according to the micromorphologic characteristics of the culture (Warren \& Hazen 1995, Hoog \& Guarro 1995).

The definition of BSI was based on that proposed by the Center of Disease Control, Atlanta, USA and it required that $\geq 1$ culture of blood samples, which were obtained in the presence of fever (body temperature $\geq 38^{\circ} \mathrm{C}$ ) not attributable to other causes, yielded bacteria or yeast (Garner et al. 1988). Cases in which a single blood culture yielded coagulase-negative staphylococci, Corynebacterium species and Bacillus species were classified as "pseudo-bloodstream infections" (Reimer et al. 1997, Kim et al. 2000).

BSI were considered nosocomial if signs and symptoms became evident $>48 \mathrm{~h}$ after admission to the hospital or if the patient had been hospitalized 2 weeks before the current admission (Garner et al. 1988). All infections due to Mycobacterium, Cryptococcus neoformans and Histoplasma capsulatum were considered as community acquired infections.

\section{RESULTS}

We were able to evaluate 111 patients $(68 \%$ male) with age ranging from 20 to 76 years (mean 36 years), exhibiting a CD4+ count between 1 and 200 (mean 64 cells). Patient's risk factors for HIV infection were as follows: non-drug users heterosexual patients $(48 \%)$, intravenous drug users $(20 \%)$, homossexuals $(7 \%)$, bissexuals $(3 \%)$, and unknown risk group (22\%).

Almost $70 \%$ of the population was under highly active antiretroviral therapy (HAART) or other regimens of antiretroviral therapy at the time they were first evaluated. Only $14 \%$ of the patients presented, at any time during the study, a total granulocytes count of $<1000$ cells $/ \mathrm{ml}$. We found that $40 \%$ of the patients had an indwelling medical device in place at the time they were sampled and $68 \%$ of them had already been exposed to previous antibiotic therapy. The main causes of hospitalization were: fever of unknown origin $28 \%$, pneumonia $25 \%$, neurologic syndromes $24 \%$, hepatoesplenic febrile syndrome $17 \%$ and chronic diarrhea $6 \%$.
A total of 54 out 111 evaluated patients exhibited positive blood cultures during the study, including 46 episodes considered as truly BSI and 8 judged as contamination. The distribution of pathogens related to BSI was as follows: $43 \%$ of episodes were caused by gram-positive bacteria, $20 \%$ by fungi, $15 \%$ by gram-negative, $15 \%$ by Mycobacterium spp. and 7\% were caused for mixed flora (Table). The rate of BSI in our population was $41 \%$, including 17 (37\%) episodes of community-acquired and $29(63 \%)$ of nosocomial-acquired infections.

The most common etiological agents of BSI were: Staphylococcus aureus (41\%), M. tuberculosis (13\%), P. mirabilis, C. neoformans, $H$. capsulatum and C. albicans (7\% each), P. aeruginosa (4\%), coagulase-negative staphylococci, A. baumanii, S. marcescens and M. avium complex ( $2 \%$ each), and mixed flora episodes (6\%).

The following agents represented community-acquired BSI: M. tuberculosis (7 episodes), $S$. aureus (4), $C$. neoformans (3), and H. capsulatum (3). Hospital-acquired BSI was represented by: $S$. aureus (15), C. albicans (3), $P$. mirabilis (3), P. aeruginosa (2), A. baumanii, coagulasenegative staphylococci and $S$. marcescens (1 each) and mixed flora infections (3).

Gram-positive bacteria were the etiologic agent responsible for 20 episodes of BSI, mostly represented by $S$. aureus hospital-acquired infections. It is noteworthy that $53 \%$ of them had a CVC in place at the time they were sampled and $66 \%$ of them were drug users. Patients with BSI for staphylococci exhibited CD4 + T lymphocyte count $<50$ cells $/ \mathrm{ml}$ in $66 \%$ of cases and a normal number of granulocytes.

Gram-negative bacteria were responsible for 7 episodes of hospital-acquired BSIs and P. mirabilis was the pathogen most commonly isolated. Gram-negative infections

\section{TABLE}

Organisms isolated from acquire immunodeficiency syndrome patients with bloodstream infections, 1997-1999

\begin{tabular}{lcr}
\hline Microorganism & Nr of patients & $\%$ \\
\hline Gram (+) & 20 & 43 \\
Staphylococcus aureus & 19 & \\
Coagulase-negative Staphylococcus & 1 & \\
Fungi & 9 & 20 \\
Yeasts & 6 & \\
Crytococcus neoformans & 3 & \\
Candida albicans & 3 & \\
Dimorphic & 3 & \\
$\quad$ Histoplasma capsulatum & 3 & \\
Gram (-) & 7 & \\
Proteus mirabilis & 3 & \\
Pseudomonas aeruginosa & 2 & \\
Acinetobacter baumanii & 1 & \\
Serratia marcescens & 1 & \\
Mycobacteria & 7 & \\
Mycobacterium tuberculosis & 6 & \\
Mycobacterium avium complex & 1 & \\
Polymicrobial & 3 & \\
\hline Total & 46 &
\end{tabular}


were mostly documented in patients who developed nosocomial pneumonia $(57 \%)$. Patients with BSI for Gram-negative bacteria presented CD4+ T lymphocyte count $<50$ cells $/ \mathrm{ml}$ in $57 \%$ of cases and a normal number of granulocytes.

C. albicans was responsible for 3 episodes of nosocomial acquired BSI and were documented in patients with more than 14 days of hospitalization and a CVC in place $(100 \%)$ at the time they were sampled. Regarding laboratory tests, patients with candidemia presented CD4+ T lymphocyte count $<100$ cells $/ \mathrm{ml}$ and a normal number of granulocytes.

Cryptococcemia ( 3 cases) was documented in patients with a history of prolonged fever related to meningeal and/or pneumonic syndromes. Regarding to laboratory tests we should emphasize that all them had a normal number of granulocytes and CD4+ T lymphocyte count $<50$ cells $/ \mathrm{ml}$.

H. capsulatum bloodstream infections (3 cases) were documented in patients with prolonged fever, hepatosplenomegaly and CD4+ T lymphocyte count $<50$ cells $/ \mathrm{ml}$.

Mycobacterium spp. infections were found in $7 \mathrm{pa}-$ tients (15\%) with a predominance of M. tuberculosis (6). Mycobacteremia was documented in patients with prolonged fever and hepatoesplenomegaly syndrome. Regarding laboratory tests, no patient presented granulocytopenia, and all them had CD4+ T lymphocyte count $<$ 50 cells $/ \mathrm{ml}$.

The crude mortality rate of our patients was $39 \%$, being $50 \%$ for patients with BSI and $31 \%$ for the others. Mortality rates of infections due to different pathogens were as follows: gram-negative bacteria $(43 \%)$, gram-positive bacteria (45\%), fungi (55.5\%) and Mycobacterium spp. $(86 \%)$. Mortality rates were $45 \%$ for hospital-acquired and $59 \%$ for community-acquired bloodstream infections.

\section{DISCUSSION}

In the present study we evaluated the prevalence of BSI in Aids patients with advanced stage of disease admitted to the hospital without diagnosis of the ongoing infection.

The main epidemiological characteristics of the Aids population included in this study was similar to that exhibited by most HIV patients in Brazil. We had a gender distribution of men 2:1 women and heterosexual transmission as the major risk factor for HIV infection.

We were able to identify 46 episodes $(41 \%)$ of bloodstream infections in 111 patients. S. aureus was the pathogen most commonly associated with BSI in this study, responding for $41 \%$ of all episodes. Despite some authors have postulated that coagulase-negative staphylococci is the major agent of bacteremia in Aids patients, other investigators have found $S$. aureus as the predominant agent of BSI among gram-positive bacteremic episodes (Whimbey et al. 1986, Jacobson et al. 1988, Schaberg et al. 1991, Banerjee et al. 1991, Emori \& Gaynes 1993, Goetz et al. 1994). The ample presence of patients with a history of intravenous drug use in our population may, in part, explain the predominance of $S$. aureus among the BSI. The use intravenous drugs as well as $S$. aureus nasal carries are both factors that had been recognized as risk factors for S. aureus bacteremia among Aids patients (Tuazon \& Sheagren 1974, Ganesh et al. 1989, Raviglione et al. 1990). Infections with gram-negative bacteria, the third cause of BSI in our patients, were related to pneumonia and neurological syndromes with reduced consciousness and necessity of mechanical ventilation. The etiologies of gramnegative BSI showed a predominance of Proteus mirabilis and Pseudomonas aeruginosa, pathogens commonly associated with nosocomial pneumonia in Brazilian institutions (Sader et al. 2001). Regarding laboratory tests, this patient population presented CD4+ T lymphocyte counts $<50$ cells/ml (70\%) and absence of neutropenia with the supposedly primary infectious focus being nosocomial pneumonia. Gram-negative BSI in Aids patients have been commonly associated with diarrhea, including agents as Salmonella sp. and Shiguella sp. (Tumbarello et al. 1995, Salavert Lleti et al. 1996). The difference between our findings and the literature may be related with the diversity of Aids patients evaluated on different series. It is noteworthy that we excluded outpatients of this study and evaluated exclusively late-stage Aids patients who required hospitalization.

The infections with Mycobacterium spp. occurred in patients with prolonged fever, hepatosplenomegaly and disseminated lymphadenomegaly and all of them presented CD4+ T lymphocyte counts $<100$ cells $/ \mathrm{ml}$. These findings are similar to those reported in other series, particularly in Latin America, where infections with Mycobacterium represent a significant public health problem. It should be pointed out that 6 of 7 Mycobacterium spp. were $M$. tuberculosis, confirming the higher prevalence of these species in causing opportunistic infections in patients with Aids in Brazil (Grynsztejn et al. 1997).

Of the many Aids-associated infections, the invasive fungal infections are relatively common, especially in patients with a CD4+ T lymphocyte count of less than 200 cells $/ \mathrm{ml}$. Yeasts of the Candida and Cryptococcus genera are the most frequently identified fungi as cause of infection in these patients (Mess \& Daar 1997). In our patients, fungemia corresponded to $20 \%$ of the episodes of infection, with the following distribution: $C$. neoformans, $H$. capsulatum and C. albicans.

As expected, C. neoformans and H. capsulatum represented the majority of the documented episodes of fungemia in our series. Otherwise, we observed a high incidence of patients with candidemia, a complication reported in $7 \%$ of our cases. It should be mentioned that all these patients presented a long period of hospitalization and multiple risk factors for candidemia, including the presence of CVC, use of long-term parenteral alimentation, antibiotics, mucosal Candida infection and surgical procedures. These findings confirm previous observations in patients with HIV infection, where candidemia appears related to patients with advanced HIV disease and multiple risk factors for candidemia including invasive medical procedures, antibiotic use, as well as Candida colonization (Launay et al. 1998, Tumbarello et al. 1999).

After reviewing the English literature, we found 4 studies evaluating BSI in Aids patients (Whimbey et al. 1986, Hickey \& Shanson 1993, Meyer et al. 1994, Tumbarello et al. 1995) using different blood culture methods (BACTEC 
NR6A, COLORBACT $®$, radiometric BACTEC 460), showing a variation of $35 \%$ to $73.4 \%$ in the proportion of BSI with gram-positive bacteria, $23.4 \%$ to $32.9 \%$ with gramnegative and 0.6 to $4.8 \%$ in candidemia. We did not find any study using systematically the isolator system in the investigation of systemic infections in patients with Aids. Data on BSI due to Candida sp. (7\%) obtained in our series were higher than those mentioned before, but equivalent to the rate found in a study with systematic evaluation of infections by necropsy (10\%) (Wilkes et al. 1988). It is possible that the difference between the indices we found for candidemia and the previously published data is due to the fact that our evaluated patients were in worst clinical status and also to the better performance of the isolator in recognizing fungemia.

The design of the present study did not allow an accurate analysis of the isolator's performance related to other diagnostic methods. However, we may say that the isolator system contributed to the diagnosis of $41 \%$ of all episodes evaluated, including infections difficult to be diagnosis as candidemia, histoplasmosis and mycobacteremia. In conclusion BSI is a common complication of Aids patients with advanced stage of disease and is related with a high rate of mortality. Blood cultures performed by lysis-centrifugation method may be a useful tool for the diagnostic of opportunistic infections in Aids patients at advanced stage of disease.

\section{REFERENCES}

Banerjee S, Emori TG, Culver DH, Gaynes RP, Jarvis WR, Horan T, Edwards JR, Tolson J, Henderson T, Martone WJ 1991. Secular trends in nosocomial primary bloodstream infections in the United States, 1980-1989. National Nosocomial Infections Surveillance System. Am J Med 91(Suppl. 3B): $86 \mathrm{~S}-89 \mathrm{~S}$.

Emori TG, Gaynes RP 1993. An overview of nosocomial infections, including the role of the microbiology laboratory. Clin Microbiol Rev 6: 428-442.

Ganesh R, Castle D, McGibbon D, Phillips I, Bradbeer C 1989. Staphylococcal carriage and HIV infection. Lancet 2: 558, letter.

Garner JS, Jarvis WR, Emori TG, Horan TC, Hughes JM 1988. CDC definitions for nosocomial infections. Am J Infect Control 16: 128-140.

Goetz AM, Squier C, Wagener MM, Muder RR 1994. Nosocomial infections in the human immunodeficiency virusinfected patient: a two year survey. Am J Infect Control 23: 334-339.

Grinsztejn B, Fandinho FCO, Veloso VG, João EC, Lourenço MCS, Nogueira SA, Fonseca LS, Werneck-Barroso E 1997. Mycobacteremia in patients with the acquired immunodeficiency syndrome. Arch Intern Med 157: 2359-2363.

Hickey MM, Shanson DC 1993. Septicaemia in patients with and without Aids at Westminster Hospital, London. J Infect 27: 243-250.

Hoog GS, Guarro J 1995. Identification. In Atlas of Clinical Fungi, Central Bureau voor Schimmelcultures, Universitat Rovira I Virgili, Spain, p. 8-12.

Jacobson MA, Gellermann H, Chambers H 1988. Staphylococcus aureus bacteremia and recurrent staphylococcal infection in patients with acquired immunodeficiency syndrome and Aids-related complex. Am J Med 85: 172-175.

Kim SD, Mc Donald LC, Jarvis WR, McAllister SK, Jerris R,
Carson LA, Miller JM 2000. Determining the significance of coagulase-negative staphylococci isolated from blood cultures at a community hospital: a role for species and strains identification. Infect Control Hosp Epidemiol 21: 213-217.

Launay O, Lorttholary O, Bouges-Michel C, Jarrousse B, Bentata M, Guillevin L 1998. Candidemia: a nosocomial complication in adults with late-stage Aids. Clin Infect Dis 26: 1134-1141.

Mess T, Daar ES 1997. Utility of fungal blood cultures for patients with Aids. Clin Infect Dis 25: 1350-1353.

Meyer CN, Skinhoj P, Prag J 1994. Bacteremia in HIV-positive and Aids patients: incidence, species distribution, risk-factors, outcome, and influence of long-term prophylactic antibiotic treatment. Scand J Infect Dis 26: 635-642.

NCCLS-National Committee For Clinical Laboratory Standards 1995. Processing and Interpretation of Blood Cultures, Document 1.7, Washington, D.C.

Petrosillo N, Viale P, Nicastri E, Arici C, Bombana E, Casella A, Cristini F, De Gennaro M, Dodi F, Gabbuti A, Gattuso G, Irato L, Maggi P, Pallavicini F, Pan A, Pantaleoni M, Ippolito $\mathrm{G}$, for Gruppo HIV e Infezioni Ospedaliere 2002. Nosocomial bloodstream infections among human immunodeficiency virus-infected patients: incidence and risk factors. Clin Infect Dis 34: 677-685.

Raviglioni MC, Mariuz P, Pablos-Mendez A, Battan R, Ottuso P, Taranta A 1990. High Staphylococcus aureus nasal carriage rate in patients with acquired immunodeficiency syndrome or Aids-related complex. Am J Infect Control 18: 6469.

Reimer LG, Wilson ML, Weinstein MP 1997. Update on detection of bacteremia and fungemia. Clin Microbiol Rev 10: 444-465.

Sader HS, Gales AC, Pfaller MA, Mendes RE, Zoccoli C, Barth A, Jones RN 2001. Pathogen frequency and resistance patterns in Brazilian hospitals: summary of results from three years of the SENTRY antimicrobial surveillance program. Braz J Infect Dis 5: 200-214.

Salavert Lletí M, Navarro Ibáñez V, Roig Rico P, Bretón Martínez JR, Ponz Díez F, López Aldeguer J, Gobernado Serrano M 1996. Bacteriemia por Pseudomonas aeruginosa en pacientes con infección por el VIH: estudio clinicoepidemiológico de 17 episodios. Rev Clín Esp 196: 684691.

Schaberg DR, Culver DH, Gaynes RP 1991. Major trends in the microbial etiology of nosocomial infection. Am J Med 91(Suppl. 3B): 72S-75S.

Tuazon CU, Sheagren JN 1974. Increased rate of carriage of Staphylococcus aureus among narcotic addicts. J Infect Dis 129: 725-727.

Tumbarello M, Tacconelli E, Caponera S, Cauda R, Ortona L 1995. The impact of bacteremia on HIV infection. Nine years experience in a large Italian university hospital. $J$ Infect 31: 123-131.

Tumbarello M, Tacconelli E, Gaetano Donati K, Morace G, Fadda G, Cauda R 1999. Candidemia in HIV-infected subjects. Eur J Clin Microbiol Infect Dis 18: 478-483.

Warren NG, Hazen KC 1995. Candida, Cryptococcus, and other yeasts of medical importance. In PR Murray, Manual of Clinical Microbiology, Washington D.C., p. 723-737.

Whimbey E, Gold JW, Polsky B 1986. Bacteremia and fungemia in patients with the acquired immunodeficiency syndrome. Ann Intern Med 104: 511-514.

Wilkes MS, Fortin AH, Felix JC, Godwin TA, Thompson WG 1988. Value of necropsy in acquired immunodeficiency syndrome. Lancet 2: 85-88. 